FEDERAL RESERVE BANK of ST. LOUIS

\section{RESEARCH DIVISION} Working Paper Series

\title{
Did Affordable Housing Legislation Contribute to the Subprime Securities Boom?
}

\author{
Andra C. Ghent, \\ Rubén Hernández-Murillo \\ and \\ Michael T. Owyang
}

Working Paper 2012-005D

https://doi.org/10.20955/wp.2012.005

December 2014

\author{
FEDERAL RESERVE BANK OF ST. LOUIS \\ Research Division \\ P.O. Box 442 \\ St. Louis, MO 63166
}

The views expressed are those of the individual authors and do not necessarily reflect official positions of the Federal Reserve Bank of St. Louis, the Federal Reserve System, or the Board of Governors.

Federal Reserve Bank of St. Louis Working Papers are preliminary materials circulated to stimulate discussion and critical comment. References in publications to Federal Reserve Bank of St. Louis Working Papers (other than an acknowledgment that the writer has had access to unpublished material) should be cleared with the author or authors. 


\title{
Did Affordable Housing Legislation Contribute to the Subprime Securities Boom?
}

\author{
Andra C. Ghent, Rubén Hernández-Murillo, and Michael T. Owyang* \\ Keywords: Mortgages, Loan Performance, Community Reinvestment Act, GSEs.
}

\begin{abstract}
We use a regression discontinuity approach and present new institutional evidence to investigate whether affordable housing policies influenced the market for securitized subprime mortgages. We use merged loan-level data on non-prime mortgages with individual- and neighborhoodlevel data for California and Florida. We find no evidence that lenders increased subprime originations or altered loan pricing around the discrete eligibility cutoffs for the GovernmentSponsored Enterprises' (GSEs) affordable housing goals or the Community Reinvestment Act. Although we find evidence that the GSEs bought significant quantities of subprime securities, our results indicate that these purchases were not directly related to affordable housing mandates.
\end{abstract}

This draft: December 9, 2014.

\footnotetext{
*Ghent: W.P. Carey School of Business, Arizona State University; phone 480-965-4689; email aghent@asu.edu. Hernández-Murillo: Research Division, Federal Reserve Bank of St. Louis; phone 314-444-8588; email: ruben.hernandez@stls.frb.org. Owyang: Research Division, Federal Reserve Bank of St. Louis; phone 314-444-8558; email owyang@stls.frb.org. The views expressed herein are those of the authors and do not reflect the official positions of the Federal Reserve Bank of St. Louis or the Federal Reserve System.
} 


\section{Introduction}

It is widely understood that the volume of subprime mortgages grew dramatically in the years immediately preceding the financial crisis of 2007-2008 and that a large fraction of these mortgages was transformed into private-label mortgage-backed securities (PLMBS). ${ }^{1}$ The volume of loan originations in the PLMBS market grew by about $750 \%$ between 2001 and 2005 . This boom, and its subsequent implosion, had major consequences for the financial sector and the macroeconomy. Understanding the causes of this boom and bust may shed light on what drives asset booms and assist in preventing future financial crises.

Some observers have argued that affordable housing policy was a causal factor in the subprime crisis. For instance, writing in the Financial Times, Raghuram Rajan (2010) writes "[t]he tsunami of money directed by a U.S. Congress, worried about growing income inequality, towards expanding low income housing, joined with the flood of foreign capital inflows to remove any discipline on home loans." When asked about the cause of the financial crisis, Eugene Fama states that "the global crisis was first a problem of political pressure to encourage the financing of subprime mortgages" (Fama and Litterman, 2012). Greenspan (2010) also asserts that affordable housing policies played a key role in the subprime crisis.

While commentators are often not specific about precisely which affordable housing policies caused the crisis, the two main affordable housing policies for owner-occupied housing in the US are the Community Reinvestment Act (CRA) and the affordable housing goals for Fannie Mae and Freddie Mac. The CRA requires depository institutions to monitor and report the amount of mortgage lending they do in low income neighborhoods and to low income individuals. CRA examiners consider how much CRA-qualified lending the institution to be examined has done over the examination period but there are not firm targets for the percentage of lending that must be CRA-qualifying to receive particular evaluations. In contrast, the Government-Sponsored Enterprises (GSEs) have specific numerical targets for the share of their lending in low income neighborhoods, to neighborhoods with high shares of minorities, and to low income individuals. The Department of Housing and Urban Development (HUD) has responsibility to set the specific numerical targets for the GSEs in consultation with the GSEs and key congressional members.

\footnotetext{
${ }^{1}$ PLMBS are mortgage-backed securities (MBS) that are issued or guaranteed by an entity other than Fannie Mae, Freddie Mac, or Ginnie Mae.
} 
Loan may count towards more than one goal. However, depository institutions and the GSEs must comply with the requirements to lend to both low income individuals and in low income neighborhoods.

Importantly, the GSEs can satisfy their affordable housing goals by purchasing packages of securitized mortgages that they do not purchase as whole loans. They receive fractional credit towards their affordable housing goals for loans they acquire exposure to through purchases of MBS. Manchester (2008) shows that the GSEs generally purchased "goal rich" PLMBS during the subprime boom. In addition to their originations, depository institutions may count PLMBS toward their CRA obligations provided the MBS are structured as CRA-qualified securities.

While there was no substantive change in the CRA during the 2000s, there were changes in the GSEs' numerical targets for their affordable housing goals. Table 1 shows the evolution of the GSEs' affordable housing goals since 1996. There is a fairly substantial increase between 2000 and 2001 with the three subgoals increasing by six to eight percentage points. However, there is no change in the goals between 2001 and 2004. Between 2004 and 2005 there is a two percentage point increase in the Special Affordable Goal (SAG) and the Low-and-Moderate-Income Goal (LMIG) and a six percentage point increase in the Underserved Areas Goal (UAG). The UAG is a geographic goal as it regards loans made to borrowers living within particular Census tracts while the SAG and LMIG goals focus on loans made to borrowers with particular characteristics.

Table 1: The GSEs' Affordable Housing Goals over Time

\begin{tabular}{|c|c|c|c|c|c|c|c|c|c|}
\hline & \multicolumn{3}{|c|}{ UAG } & \multicolumn{3}{|c|}{ SAG } & \multicolumn{3}{|c|}{ LMIG } \\
\hline & & FNMA & FHLMC & & FNMA & FHLMC & & FNMA & FHLMC \\
\hline & Goal & Actual & Actual & Goal & Actual & Actual & Goal & Actual & Actual \\
\hline 1996 & $21 \%$ & $28 \%$ & $25 \%$ & $12 \%$ & $15 \%$ & $14 \%$ & $40 \%$ & $46 \%$ & $41 \%$ \\
\hline 1997 & $24 \%$ & $29 \%$ & $26 \%$ & $14 \%$ & $17 \%$ & $15 \%$ & $42 \%$ & $46 \%$ & $43 \%$ \\
\hline 1998 & $24 \%$ & $27 \%$ & $26 \%$ & $14 \%$ & $14 \%$ & $16 \%$ & $42 \%$ & $44 \%$ & $43 \%$ \\
\hline 1999 & $24 \%$ & $27 \%$ & $28 \%$ & $14 \%$ & $18 \%$ & $17 \%$ & $42 \%$ & $46 \%$ & $46 \%$ \\
\hline 2000 & $24 \%$ & $31 \%$ & $29 \%$ & $14 \%$ & $19 \%$ & $21 \%$ & $42 \%$ & $50 \%$ & $50 \%$ \\
\hline 2001 & $31 \%$ & $33 \%$ & $32 \%$ & $20 \%$ & $22 \%$ & $23 \%$ & $50 \%$ & $52 \%$ & $53 \%$ \\
\hline 2002 & $31 \%$ & $33 \%$ & $31 \%$ & $20 \%$ & $21 \%$ & $20 \%$ & $50 \%$ & $52 \%$ & $51 \%$ \\
\hline 2003 & $31 \%$ & $34 \%$ & $32 \%$ & $20 \%$ & $21 \%$ & $21 \%$ & $50 \%$ & $52 \%$ & $51 \%$ \\
\hline 2004 & $31 \%$ & $42 \%$ & $34 \%$ & $20 \%$ & $24 \%$ & $23 \%$ & $50 \%$ & $53 \%$ & $52 \%$ \\
\hline 2005 & $37 \%$ & $44 \%$ & $41 \%$ & $22 \%$ & $26 \%$ & $24 \%$ & $52 \%$ & $55 \%$ & $54 \%$ \\
\hline 2006 & $38 \%$ & $44 \%$ & $44 \%$ & $23 \%$ & $28 \%$ & $26 \%$ & $53 \%$ & $57 \%$ & $56 \%$ \\
\hline 2007 & $38 \%$ & $40 \%$ & $43 \%$ & $25 \%$ & $27 \%$ & $26 \%$ & $55 \%$ & $56 \%$ & $56 \%$ \\
\hline 2008 & $39 \%$ & $42 \%$ & $39 \%$ & $27 \%$ & $26 \%$ & $23 \%$ & $56 \%$ & $54 \%$ & $52 \%$ \\
\hline
\end{tabular}

Notes: 1) Source, FHFA (2010). 2) UAG refers to the underserved areas goal, SAG refers to the Special Affordable Goal, and LMIG refers to Low-and-Moderate-Income Goal. 3) See text of paper for goal eligibility criteria. 
The existing literature finds little effect of affordable housing mandates on mortgage markets has not convinced the proponents of the view that affordable housing mandates caused the crisis. Early examples of the literature finding no or negligible effects include Ambrose and Thibodeau (2004) and Bostic and Gabriel (2006); see also the literature cited therein. Bhutta (2012), Bolotnyy (2014), and Moulton (2014) use a regression discontinuity approach and study loans that the GSEs could purchase as whole loans. Bhutta (2012) and Bolotnyy (2014) focus only on the UAG goal while Moulton (2014) studies all three GSE goals. While all three papers focus on the prime, rather than the subprime market, they all find small to no effects of the goals on loan supply. Reid and Laderman (2011) focus on the originator of the loan, since the CRA only applies to depository institutions, and show that the majority of subprime loans were originated by non-depository institutions. Using a regression discontinuity approach similar to ours, Bhutta (2011) shows that, over the 1994 2006 period, the CRA geographic goal had an economically and statistically significant effect on lending in large cities in the late 1990s and early 2000s but that the effect had disappeared by the mid-2000s. Agarwal, Benmelech, Bergman, and Seru (2012) look at whether the volume of loan originations changes around the CRA evaluation date and find significantly more originations in the three quarters before the evaluation date (not the evaluation period) and three quarters after the evaluation date. In contrast to Bhutta's (2011) findings, Agarwal, Benmelech, Bergman, and Seru (2012) find that these effects of the CRA on loan volume were largest during the subprime boom. See Reid et al. (2013) for a discussion of Agarwal, Benmelech, Bergman, and Seru (2012).

While some of the analysis in our paper uses a methodology similar to some of the previous literature, our formal empirical analysis addresses two important issues that previous literature does not address. Most importantly, all mortgages in our 2004-2006 sample were packaged into subprime PLMBS. ${ }^{2}$ To ensure that we look at only these mortgages, we match HMDA data to loan-level data from PLMBS deals. No previous paper has done this. As a consequence, previous work has been unable to assess whether affordable housing policies contributed to the subprime securities boom. Indeed, previous literature has only been able to use proxies for subprime such as whether HMDA defines the loan as high cost (e.g., Reid and Laderman, 2011; Moulton, 2014)

\footnotetext{
${ }^{2}$ Our data also contains loans that were packaged into "alt-A" deals. These deals were not marketed to investors as subprime deals. We use the term subprime for consistency with the common usage of the term subprime after the financial crisis and because, ex post, loans in "alt-A" deals performed more similarly to loans packaged into subprime securities.
} 
or was originated by an institution that was at one point in time designated by the Department of Housing and Urban Development (HUD) (Bhutta, 2012). In our matched data, we find that only about half of subprime mortgages were high cost loans. HUD discontinued publication of its list of designated subprime originators out of accuracy concerns suggesting that it may not be a strong proxy for a loan packaged into subprime securities. Second, our matched dataset reveals that the majority of mortgages in subprime PLMBS did not go to low income borrowers. Rather, we find that average stated borrower income for these loans is over $\$ 100,000$ which is more than twice as high as the income of the census tract. Hence, any income falsification, as was done with low or no documentation mortgages, was more likely to be upwards rather than downwards.

Our regression discontinuity approach identifies the effect of the act by looking at origination volumes, interest rates, and default rates near the goal thresholds. Because the goal thresholds are discrete, if the goals are binding we should expect to see, for example, lower interest rates on loans to borrowers with incomes just below the income thresholds for each of the borrower-specific goals than on loan loans to borrowers with incomes just above the income thresholds. We use this approach because it does not rely on the loan originator being the final holder of the loan. We find no evidence that affordable housing legislation affected the subprime market during the subprime crisis. Lending volumes, loan pricing, and default rates do not change in response to the goals. The point estimates are close to zero and the standard errors are small.

As the regression discontinuity approach identifies only local average treatment effects, we also adduce new relevant institutional details. In particular, we evaluate 100 randomly chosen prospectus supplements to assess how, if at all, they discuss how the loans satisfy affordable housing goals or whether the securities were CRA-qualified. We also use our sample of prospectus supplements to examine the extent to which MBS were tailored to satisfy GSE demand.

The institutional evidence indicates that it is highly unlikely that institutions were satisfying their affordable housing goals in the PLMBS market. In a random sample of 100 prospectus supplements for nonprime PLMBS that we examine, not a single prospectus ever mentions the GSEs' affordable housing goals or the CRA despite discussing at length numerous other characteristics of the loans in the pools. Put differently, none of the pools we examine were CRA-qualified. This finding is particularly strong evidence that the CRA did not affect the market since depository institutions can only get credit for purchases of PLMBS that are specifically structured as CRA- 
qualified. Consistent with the findings of Reid and Laderman (2011), we find that the majority of loans securitized in PLMBS were originated by non-depository institutions that were not subject to the CRA indicating the presence of substantial incentives to originate such loans by institutions that were not subject to the CRA.

However, the prospectus supplements reveal that the GSEs were major purchasers of PLMBS. Our review of the sample of prospectus supplements provides us with a rough estimate, $25 \%$, of the GSEs' share of the market for the senior tranches of PLMBS deals. As such, it remains plausible that the GSEs encouraged subprime lending by purchasing large quantities of PLMBS. However, our results indicate that any role the GSEs played in the subprime crisis was not due to their affordable housing mandates.

\section{Empirical Methodology}

To assess whether affordable housing laws led to the subprime housing boom, we must first examine the mechanisms through which the change in laws could affect lending behavior. We investigate whether these laws led to a change in lender behavior to meet the programs' objectives. For example, changes in lending behavior could manifest as a relaxation in lending standards or a change in mortgage pricing. In this section, we outline each program's objectives. We then describe three channels through which lenders could respond to these regulations, thereby inducing a boom in subprime lending and securitization. We then test whether lender behavior did indeed change for these variables just below the programs' cutoffs.

\section{The Affordable Housing Goals}

The affordable housing goals for the CRA and the GSEs are actually seven separate goals. Two of the goals are CRA performance evaluation benchmarks and five are the GSEs' affordable housing targets. Some of the goals apply to borrowers living within a particular Census tract and some of the goals are specific to individual borrowers regardless of where they live. The loans that satisfy each of the goals are as follows:

1. CRA1: Loans to borrowers living in Census tracts with median tract to metropolitan statistical area (MSA) income of $80 \%$ or less.

2. CRA2: Loans to borrowers with incomes of $80 \%$ or less of the median MSA income. 
3. UAG1: Loans to borrowers living in Census tracts with a minority population of $30 \%$ or more and median tract to MSA income of $120 \%$ or less.

4. UAG2: Loans to borrowers living in Census tracts with median tract to MSA income of $90 \%$ or less.

5. SAG1: Loans to borrowers with incomes of $60 \%$ or less of the median MSA income.

6. SAG2: Loans to borrowers with incomes of $80 \%$ or less of the median MSA income and who live in Census tracts with median tract to MSA income of $80 \%$ or less.

7. LMIG: Loans to borrowers with incomes of $100 \%$ or less of the median MSA income.

Financial institutions subject to these regulations must meet both the borrower-specific and tract-specific goals. That is, the GSEs are given specific targets for each of the three goal areas (UAG, SAG, and LMIG) and depository institutions must satisfy both CRA1 and CRA2. As such, institutions cannot satisfy their goals solely by making loans to high income households that live in low-income neighborhoods. As Table 1 shows, the borrower-specific GSE goals were much closer to being binding in the mid-2000s than the geographic GSE goal.

None of our goal thresholds coincide with the major affordable rental program in the United States, the low income housing tax credit (LIHTC). See Baum-Snow and Marion (2009) for a discussion of the LIHTC. The CRA1 limit coincides with the moderate income definition for the community development block grant (CDBG) program of HUD. The CDBG program provides funds for a diverse set of community development projects such as public infrastructure, rehabilitating dilapidated homes, parks, homeless facilities, programs for battered spouses, employment training, and other services for low income communities. The funding amounts are not discretely determined by a goal threshold but, rather, are allocated "using a formula comprised of several measures of community need, including the extent of poverty, population, housing overcrowding, age of housing, and population growth lag in relationship to other metropolitan areas" (HUD, 2012). Furthermore, although the amount of funding each state and city receives depends on the portion of its population that is moderate income, the organizational unit that receives the funds is not a census tract but rather a state, county, or municipality. The program is also not related to funding for home ownership. It is thus highly unlikely that it affects our identification strategy below. 


\section{The CRA}

The CRA was enacted in 1977 and was strengthened over time. During our sample period, the policy was enforced by four separate regulators: the Federal Deposit Insurance Corporation, the Federal Reserve, the Office of the Comptroller of the Currency, and the Office of Thrift Supervision. The act encourages depository institutions to lend to low-income communities and to low-income individuals. While the CRA does not have an explicit racial component, the high correlation between the racial and income characteristics of neighborhoods and individuals implies that the CRA indirectly addresses concerns about racial disparities in credit access. ${ }^{3}$ Institutions get CRA credit for qualifying loans that they originate.

CRA-related regulations stipulate that some qualifying loans in an MBS that a depository institution acquires may also be used to fulfill the goal (Office of the Comptroller of the Currency et al., 1997). In particular, MBS structured specifically to help an institutional MBS purchaser meet the CRA goals will generally count toward fulfilling the requirement. A CRA-qualified MBS is one that is specifically designed to include loans from specified geographies that include the depository institution's assessment area (Federal Reserve Bank of San Francisco, 2010). Furthermore, for an MBS to be CRA-qualified, at least $51 \%$ of the loans in it must be to borrowers that have $80 \%$ or MSA median income (Federal Reserve Bank of San Francisco, 2010). Importantly, the regression discontinuity approach used below allows us to capture the effect of affordable housing legislation on securitized loans.

CRA compliance is accomplished by regularly scheduled evaluations. Depending on the size of the institution, regulators evaluate the institution either every two or five years. Large banks are evaluated every two years and all of their lending data for the evaluation period is used during the evaluation period. The smallest banks are evaluated every five years and, for such institutions regulators sometimes choose to examine only a subsample of two to three years of lending data, rather than all lending over the full five year evaluation period. Institutions know the year in which their exam will occur although they may not know in exactly which quarter until the year of the exam. ${ }^{4}$ The data used to evaluate each institution is all the institution's lending since the previous

\footnotetext{
${ }^{3}$ For a review of the literature on race, redlining, and mortgage lending, see Ross and Yinger (2002). More recent contributions to this literature include Haughwout, Mayer, and Tracy (2009) and Ghent, Hernández-Murillo, and Owyang (2014).

${ }^{4}$ To our knowledge, the only event that may allow a bank to delay its regular CRA evaluation is a merger.
} 
exam up until anywhere from a few days to three quarters before the exam. ${ }^{5}$

Importantly, CRA evaluations explicitly consider the proportion of lending to both low income households as well as to low income neighborhoods. A loan may be used to meet more than one benchmark such that there is a greater benefit from a loan that meets two benchmarks than one that meets only one benchmark. Notably, the lending component is only one aspect of the CRA evaluation. Regulators also consider any charitable contributions that the institution makes to its community and any community service its executives participate in.

\section{The GSEs' Affordable Housing Goals}

Since 1992, Fannie Mae and Freddie Mac have had numerical targets for the UAG, SAG, and LMIG. The annual targets for their share of lending that meets the criteria of the UAG, SAG, and LMIG are arrived at through a rule-making process that involves HUD, the GSEs, and Congress. A loan may be used to meet more than one goal. The definitions of qualifying loans for each of the goals are in the Housing Enterprises Financial Safety and Soundness Act of 1992 (the 1992 GSE Act). Part 81.16 of Title 24 of the Code of Federal Regulations makes it clear that a qualifying loan acquired by a GSE via a purchase of PLMBS will generally count towards the GSE's affordable housing goals. The GSEs receive fractional credit towards their affordable housing goals for PLMBS purchases in proportion to the share of the loan they hold.

\section{Identifying the Effect of Affordable Housing Legislation}

One direct way to determine whether affordable housing legislation contributed to the subprime securities boom is to measure the extent to which the laws led to more mortgage originations for the targeted groups than for other groups. For the tract-specific goals (CRA1, UAG1, and UAG2), we test whether there is a statistically significant increase in originations per Census tract divided by tract population just below versus just above the program cutoff. In this case, the dependent variable is the number of originations, a tract-level rather than a borrower-level variable. An increase in the number of originations would suggest that lenders made a conscious attempt to make loans to borrowers in the target group, which could have led to the subprime securities boom.

\footnotetext{
${ }^{5}$ For example, Piedmont Federal Savings Bank is regulated as an intermediate small savings bank such that it must undergo evaluation every two years. Its most recent evaluation date was April 25th, 2011. The lending that the Office of Thrift Supervision considered for Piedmont Federal Savings Bank in the April 2011 evaluation was all lending from January 1, 2008 through December 31st, 2010 because Piedmont Federal Savings Bank's previous exam occurred in December 2008.
} 
The volume of originations is not well suited to studying the borrower-level goals using our data since we would, in principal, only have one data point (the total volume of originations) for each income level. Moulton (2014) identifies the effect of the borrower-level goals using application disposition information in HMDA wherein each observation is a loan application. However, the categories of sale in the HMDA data are too broad to enable us to identify whether a loan was subprime. Furthermore, the HMDA data only contain information on sales of the loans for loans sold in the same year as they are originated. The interest of this paper is specifically on subprime PLMBS such that we focus on rates and performance to measure the effects of the borrower-specific goals on the subprime PLMBS market.

The regulations could also have encouraged lending is by inducing lenders to lower prices for the target groups. For all goals, we can test whether there is a discontinuity in the interest rate the borrower receives just above versus just below the program cutoff. Thus, the dependent variable in these tests is the mortgage rate charged at origination.

Alternatively, the programs could have encouraged lending is by relaxing lending standards, that is, by lending to borrowers targeted by the program who have an unusually high probability of defaulting on the loan. To explore this possibility, we can examine whether the programs affected the probability of default by the target group of borrowers. Thus, the dependent variable for these tests is a binary indicator of whether the borrower had a serious default within the first two years of origination.

\section{Regression Discontinuity Design}

We can evaluate the affordable housing programs by estimating their effect on the variables in the preceding subsection using a regression discontinuity approach (Thistlethwaite and Campbell, 1960), which takes advantage of the precise cutoffs in the objectives of the affordable housing regulations. The regression discontinuity approach has been used widely in economics and finance to improve identification of a "treatment" on a variable of interest, $Y$. Suppose that $Y$ changes smoothly with an observable variable, $X$, and the treatment, affordable housing legislation in our case, is applied only to individuals whose $X$ is restricted to be either below (or above) a known threshold $c$. The effect of the treatment can be identified from the difference between $X$ 's effect on individuals just above and just below c. Lee and Lemieux (2010) survey the use of regression 
discontinuity in economics.

To formalize, our regression discontinuity design begins by first considering the following regression:

$$
Y=\alpha+X \beta+I_{[X<c]} \tau+Z \delta+\varepsilon
$$

where $Y$ denotes, in separate regressions, mortgage originations or interest rates (the estimated probabilities of default are discussed separately below). The variable $X$ represents the observable variable that determines the treatment criteria reflected in the indicator $I_{[X<c]}$. Only those individuals with $X$ less than the cutoff, $c$, receive the treatment. The coefficient, $\beta$, represents the effect of $X$ on $Y$ sans the treatment and $\tau$ is the magnitude of the treatment effect. Here, $Z$ represents a second set of observable variables that are unrelated to the treatment criteria, $X<c$. Because the treatment criterion is known and a function of an observable variable, we need not include all variables that can affect $Y$ in $Z$. That is, there is no omitted variable bias for excluded elements of $Z$ so long as the excluded $Z$ 's are not correlated with $I_{[X<c]}$ (see Hahn, Todd, and van der Klaauw, 2001). ${ }^{6}$ Including covariates in the regression can, however, reduce sampling uncertainty and thus provide more precise estimates. See Lee and Lemieux (2010) for additional discussion of the use of covariates in regression discontinuity designs.

The treatment effect would be straightforward to estimate if the model were truly globally linear. An advantage of the regression discontinuity approach is that it relies only on local smoothness in the effect of the observable variable $X$ to identify the treatment effect. To exploit this, we can restrict our attention to loans just above and just below regulatory cutoffs. Thus, when estimating the baseline model, we include only data within a band of $2 \%$ of the goal cutoff. For example, to evaluate the effect of the CRA, we estimate using only loans made in Census tracts with median income of $78 \%$ to $82 \%$ of the MSA median income. The treatment group, i.e., the loans for which the indicator variable, $I_{[X<c]}$, takes a value of 1 , are loans made in Census tracts with median income of $78 \%$ to $80 \%$ of that of the MSA. The size of the band, in this case, $2 \%$ on each side of the cutoff, must be small enough to ensure smoothness but large enough to obtain a sufficient amount of data. We experiment with the bandwidth size to verify the robustness of our results.

\footnotetext{
${ }^{6}$ The correlation between $X$ and $Z$ does not affect the estimation of the treatment effect.
} 
For the regression discontinuity approach, we also must assume that agents (i.e., borrowers) cannot control $X$, which is innocuous for the affordable housing criteria applied to an area (e.g., a Census tract). However, in three cases (CRA2, SAG2, and LMIG), the goal is defined for an individual's income alone. Thus, it is possible that a borrower could report income just below the threshold to qualify for treatment. This assumes, however, that borrowers are keenly aware of the goals and they know lenders will, say, lower their mortgage rate. We address these issues below.

In addition to the linear model, we can estimate the effects of the affordable housing legislation on, for example, the probability of default. For the regression discontinuity model of default, we must modify the linear specification (1) to account for the binary default indicator as the dependent variable. This is also straightforward in the regression discontinuity framework, as the underlying assumption is smoothness as opposed to linearity. Thus, we can estimate the standard probit model augmented with the treatment indicator and restricted to the loans just above and just below the program cutoff. We can then assess whether the programs had an effect on the probability of default as

$$
\operatorname{Pr}[D=1]=\Phi\left(\alpha+X \beta+I_{[X<c]} \tau+Z \delta\right)
$$

where $D$ is the default indicator and $\Phi($.$) represents the standard normal cumulative distribution$ function.

In the case of affordable housing programs, the cutoffs are based on either borrower income or Census tract characteristics as described above. The advantage of our regression discontinuity approach is that we need not know who the final holder of the loan is. This point is important because financial institutions receive credit for loans that they acquire by purchasing securitized pools, not just the loans they originate or acquire as whole loans. The majority of subprime loans were securitized such that the originator is highly unlikely to be the final holder of the loan. Because depository institutions and the GSEs can satisfy their affordable housing mandates by purchasing MBS, whether the originator is subject to the CRA, whether the loan is in the financial institution's CRA assessment area, and whether the loan is conforming conveys at best incomplete information about the impact of the regulations.

In total, we estimate our three outcome measures on the following subsamples of the population 
of loans:

1. CRA1: Loans in Census tracts with median income of $78 \%-82 \%$ of MSA median income.

2. CRA2: Loans to borrowers with income of $78 \%-82 \%$ of MSA median income.

3. UAG1: Loans in Census tracts with a minority population of $28 \%-32 \%$ and with a median income of no more than $120 \%$ of MSA median income.

4. UAG2: Loans in Census tracts with median income of $88 \%-92 \%$ of MSA median income.

5. SAG1: Loans to borrowers with income of $58 \%-62 \%$ of MSA median income.

6. SAG2: Loans to borrowers with income of $78 \%-82 \%$ of MSA median income and who live in a Census tract with median income of $78 \%-82 \%$ of MSA median income. For SAG2, the treatment group is the set of borrowers that have an income of $78 \%-80 \%$ of MSA median income and who live in a Census tract with a median income of $78 \%-80 \%$ of MSA median income.

7. LMIG: Loans to borrowers with income of $98 \%-102 \%$ of MSA median income.

If any of the affordable housing goals affect the subprime market, we would expect to see a discontinuity in originations, interest rates, or default rates related to either 1) the median income in the Census tract relative to the MSA, 2) the minority population share in the Census tract, or 3) the ratio of borrower income to median MSA income. This would manifest in the statistical significance of the coefficient $\tau$.

In all models, we include the goal variable (e.g., tract-to-MSA income ratio in the regressions and probit for CRA1) as a control because our outcomes may depend on the goal variables in a continuous fashion. For example, the volume of originations may be higher in higher income neighborhoods. In the regressions for the number of originations, we always include year dummies. In the regressions for the rate and default, we include dummies for the month of origination. As a robustness check, we include other covariates in the equations. 


\section{Data}

Our data are subprime, securitized, first-lien mortgages on one-unit properties originated in 2004 through 2006 in metropolitan areas of California and Florida. We chose our sample period to coincide with the height of the subprime mortgage boom. We focus on California and Florida as these states had large shares of subprime mortgage originations and experienced a large share of defaults during the housing bust. We merge detailed data on the terms and performance of loans securitized into private-label asset-backed securities from First American CoreLogic (CL) with data on borrower income, borrower race, Census tract income, and Census tract racial composition obtained under the Home Mortgage Disclosure Act (HMDA). HMDA requires residential mortgage originators to report to the Federal Financial Institutions Examination Council certain key information on most of the loans they originate to facilitate the evaluation of compliance with the Fair Housing Act (1968) and the CRA. We restrict our sample to loans made in metropolitan areas because rural originations are often exempt from the HMDA reporting requirements. Some of our mortgages were securitized in packages that CL designates as alt-A and some were part of securities designated as B/C collateral in CL. The designations of either alt-A or B/C are security-level rather than loan-level designations. Although alt-A deals were marketed to investors as comprised of loans that were very high quality except for a lower level of documentation, most alt-A deals contain many loans with very high LTVs and low FICO scores. Similarly, most securities designated as B/C contain many loans with low or no documentation.

\section{Merging Datasets}

The matching procedure considers first-lien loans with the same purpose (purchase or refinance) and occupancy status (owner-occupied). CL associates each loan with a 5-digit U.S. Postal Service ZIP code, whereas HMDA loans are associated with Census tracts. To match ZIP codes with Census tracts we used Census Bureau ZIP Code Tabulation Areas (ZCTAs). ${ }^{7}$ We also use the geographic information systems program ArcView to establish Census tract search areas associated with any given ZCTA as follows: For each loan in CL, we determined the smallest set of Census tracts that intersect with the associated ZCTA and we allowed for the union of the Census tracts

\footnotetext{
${ }^{7}$ ZCTAs are statistical entities developed by the Census to tabulate summary statistics from the 2000 Census for geographic areas that approximate the land area covered by each ZIP code.
} 
in the intersection to extend over the geographic area defined by any given ZCTA.

Except for the use of ZCTAs, we followed Haughwout, Mayer, and Tracy's (2009) matching algorithm very closely. The procedure entails six stages that use the originator's name, the loan amount, and the origination dates to obtain the matches. The names are provided by the lenders themselves in the HMDA data but not in the CL data. As a result, lender names in CL must be cleaned manually before the matching. Loan amounts are provided in dollars in CL, while they are provided in thousands of dollars in HMDA. Furthermore, HMDA allows lenders to round up loan amounts to the nearest thousand dollars if the fraction equals or exceeds $\$ 500$. The dates are matched to within five business days if the CL dates are not imputed or to the same month if they are. ${ }^{8}$ A summary of the various stages is as follows:

- Stage 1 considers loans with matched originator names and uses the larger 4-digit ZCTA search areas. Loan amounts are matched allowing a difference of up to and including $\$ 1,000$.

- Stage 2 ignores originator names and uses 4-digit ZCTA search areas, as in stage 1.

- Stage 3 again considers originator names, but uses the smaller 5-digit ZCTA search areas. Loan amounts are matched allowing a difference of up to but not including $\$ 1,000$.

- Stage 4 is similar to stage 3 but ignores originator names.

- Stage 5 is similar to stage 1 but loan amounts are matched to within $2.5 \%$ of the CL amount.

- Stage 6 is similar to stage 2 but loan amounts are matched to within $2.5 \%$ of the CL amount.

At the conclusion of each stage, only one-to-one matches are kept and are removed from the datasets, while loans with multiple matches (either one CL loan to many HMDA loans or many CL loans to one HMDA loan) are returned to the matching pool for the subsequent stages. We also applied various data checks to the final sample of loans, including dropping observations with missing or erroneous (outside the range 300-850) FICO scores and dropping observations with contract rates smaller than the reported HMDA spread of the loan's annual percentage rate with a Treasury security of comparable maturity. For additional details on the matching algorithm, see

\footnotetext{
${ }^{8} \mathrm{CL}$ origination dates are considered to be imputed if they are exactly two months before the first payment date.
} 
the appendix of Haughwout, Mayer, and Tracy (2009). We are able to match $67 \%$ and $83 \%$ of the CL loans in California and Florida, respectively, with HMDA data.

We focus on mortgages packaged into PLMBS because much of the controversy surrounding the GSEs regards their holdings of PLMBS. There is good reason for concern regarding the GSEs' holdings of these securities. First, by 2005 Fannie Mae and Freddie Mac held more than $\$ 350$ billion of PLMBS on their respective balance sheets (Congressional Budget Office [CBO], 2010). The pattern of the GSEs' holdings of PLMBS mimics the shape of the subprime mortgage bubble (CBO, 2010). Further, the initial credit losses at the GSEs came from their holdings of PLMBS (CBO, 2010). In this paper, we do not dispute the role of PLMBS in the GSEs' downfall but rather whether the affordable housing mandates were responsible for the GSEs' role in this market.

We focus on 30-year adjustable-rate mortgages (ARMs) as we have the most data for these product types; our samples for other product types are much smaller, making it more difficult to detect any regression discontinuity that may exist. ${ }^{9}$ Our 30-year ARM definition emphasizes amortization; all mortgages in our sample amortize on a 30 year schedule. Many of our 30-year ARMs were hybrid ARMs insofar as the first interest rate adjustment came at the end of two or three years. We focus on a single product type as the regression discontinuity approach works better with greater uniformity in the variable of interest along other dimensions. The appendix provides results for the two next most common product types (5-year ARMs and 30-year FRMs) as well as for all products combined together with product type controlled for using product dummies.

In our analysis, we focus on the initial contract interest rate rather than the annual percentage rate (APR) or the margin for the ARM because there is little evidence that lenders price the default or prepayment risk of subprime ARMs using the reset rate (see Haughwout, Mayer, and Tracy, 2009 and Ghent, Hernández-Murillo, and Owyang, 2014 for discussions of this issue). The reason lenders seem to price ARMs using the initial contract rate is that a large fraction of mortgages terminate before they reach the reset date (see, e.g., Demyanyk, 2009) such that the reset rate that the margin determines is largely a hypothetical interest rate. As such, it is highly unlikely that originators offer a lower margin to borrowers whose loans meet the housing goal criteria. Because the APR is computed assuming the mortgage is held to maturity, it largely also reflects the reset rate, a rate that is hypothetical for most borrowers.

\footnotetext{
${ }^{9}$ Adelino, Frame, and Gerardi (2014) find that the majority of loans in PLMBS designed for the GSEs were ARMs.
} 
Finally, our data include a handful of observations that have implausibly small or large loan amounts, FICO scores, or LTVs. To remove the effect of such observations, which are most likely due to data entry errors, we winsorize observations in the bottom $0.5 \%$ or top $0.5 \%$ of the distribution of loan amount, FICO score, or LTV after matching.

\section{Summary Statistics}

Table 2 contains summary statistics on the loans in our sample. In total, our sample contains 722, 157 loans. About $70 \%$ of the loans in our sample satisfy at least one affordable housing goal. More than half the loans (56\%) are in Census tracts with a minority share of at least $30 \%$ such that they satisfy the GSEs' UAG1 goal. More than half the loans (54\%) also satisfy the GSEs' UAG2 goal insofar as they are for properties in Census tracts with tract income no more than $90 \%$ of that of the MSA. About $40 \%$ of the loans are made to borrowers in Census tracts with tract income of no more than $80 \%$ of MSA income such that they meet the CRA1 goal.

A smaller proportion of the loans meet the borrower-specific affordable housing goals than satisfy the tract-specific affordable housing goals. The average borrower income is over $\$ 100,000$ so these loans did not generally go to households that were low income according to the loan application. ${ }^{10}$ Only $27 \%$ of the loans are to borrowers with less than the median MSA income such they qualify for the GSEs' LMIG goal. Only $14 \%$ of the loans are made to households with income of less than $80 \%$ of the MSA's income such that they meet the CRA's borrower-specific component (CRA2). A mere $5 \%$ of loans are made to households with income of less than $60 \%$ of the median MSA income such that they meet the SAG1 criterion.

The first three rows of Table 2 provide further evidence that subprime loans were not made to households that stated they had low incomes but were disproportionately originated in low-income and minority neighborhoods. The average borrower-to-MSA median income ratio in our sample is $173 \%$ which indicates that the typical subprime borrower had a much higher stated income than the typical household in the MSA. The typical borrower in our sample lived in a Census tract where $47 \%$ of the population belonged to a racial minority and where the income in the Census tract was lower than that of the MSA.

The picture that emerges of the subprime borrower is that of a high-income household that lives

\footnotetext{
${ }^{10}$ High borrower income is also a characteristic of products other than the 30 -year ARMs as the average borrower income over all product types is over $\$ 107,000$.
} 


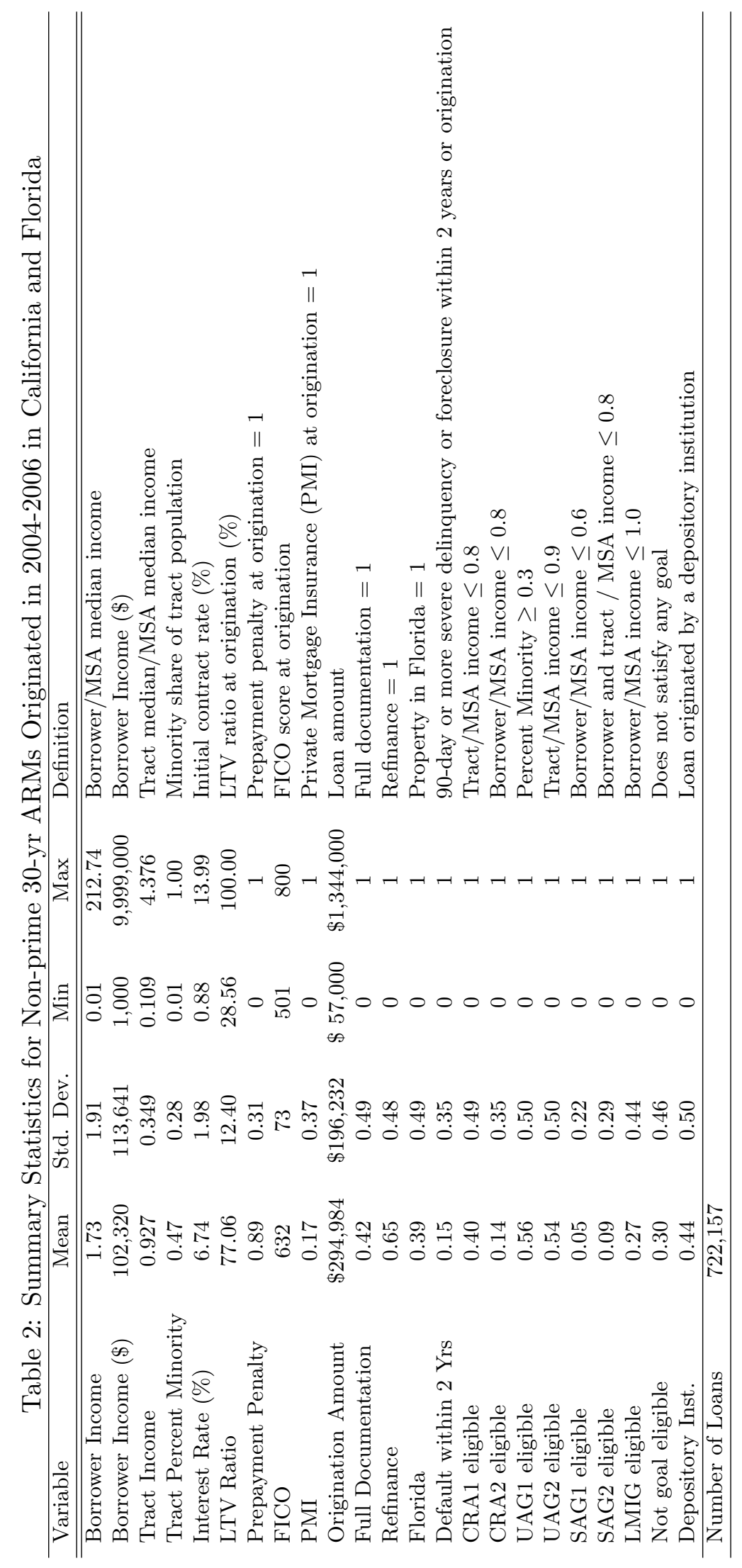


in a low-income neighborhood. Given the level of misrepresentation in the low documentation or no documentation loans (see, e.g., Jiang, Nelson, and Vytlacil, 2014), it is quite possible that the difference between the borrower's and the neighborhood's income is due to income misreporting. Fewer than half the loans in our sample are made with full documentation but even the full documentation loans may have overstated income. Regardless of the reason for the difference between the stated income of the borrower and the income in his or her neighborhood, the stated income determines eligibility for the borrower-specific goals such that few of the loans in our sample qualify for the borrower-specific goals. This finding suggests that borrowers and loan originators overstated borrower incomes in order to get loans originated. If lenders were struggling to meet their affordable housing mandates, we would expect to see understatement of borrower incomes so that more loans were eligible for the goals. The evidence Jiang, Nelson, and Vytlacil (2014) present also indicates borrowers overstated rather than understated their financial positions.

Less than half the loans in our sample were originated by depository institutions. The share of loans originated by non-depository institutions is similar for other product types: for all products, $55 \%$ of loans are originated by non-depository institutions. Thus, if the CRA affected the subprime securities market, it must have been because depository institutions purchased large amounts of the securities rather than because the CRA compelled them to originate subprime loans.

The remaining characteristics of the loan in our sample are as follows:

- Average loan amount: $\$ 294,984$

- Average FICO score in our sample is 632 . This is consistent with the typical characterization of a subprime loan as one made to a borrower with a weak credit history

- Loans with a prepayment penalty at origination: $89 \%$

- Loans made to refinance an existing loan (rather than to purchase a property): $65 \%$

- Average interest rate at origination: $6.74 \%$

- Loans defaulting within 2 years of origination: $15 \%$

- Loans originated in Florida: 39\%. 


\section{Results}

\section{Baseline Results}

Figures 1 through 5 present the relationship of originations and interest rates with the goal variables using data from 2005. The figures are quite similar using data for 2004 and 2006. We group both originations and interest rates into 2-percentage-point bins for the relevant goal variable. The figures include the data associated with a particular point as all the data from the bottom of the bin cutoff to the top of the bin cutoff. For example, the point associated with $79 \%$ includes all the data from $78 \%$ to $80 \%$. The results are similar when we group originations and interest rates in 1 and 5- percentage-point bins; these results are available in the appendix.

Figures 1 and 2 show the relationship between the number of originations per tract (scaled by tract population) with the tract-to-MSA median income ratio and the percent of minority residents in the Census tract. Figures 3 through 5 show the relationship between the average initial contract interest rate and the goal variables. Figure 3 shows the relationship between the average borrower interest rate and the tract-to-MSA median income ratio; Figure 4 illustrates the relationship between the average borrower interest rate and the percent of minority residents in the Census tract. Figure 5 plots the relationship between the average borrower interest rate and the borrower-to-MSA income ratio.

If either the CRA1 or UAG1 goals fueled the subprime mortgage boom, we would expect to see a discontinuity around 80\% (CRA1) or 90\% (UAG1) in Figures 1 and 3. No discontinuity exists around either of these points. Similarly, in Figures 2 and 4, we would expect to see a discontinuity around 30\% (UAG1) if the minority share goal for the GSEs has an effect on the subprime market. We see no such effect. Finally, an effect of the borrower-specific affordable housing goals would result in a discontinuity at 60\% (SAG1), 80\% (CRA2 and SAG2), or 100\% (LMIG) in Figure 5. The results are striking: There is no visible discontinuity in either interest rates or loan originations in any of the figures.

Table 3 presents the results from our regression discontinuity approach for originations per tract per year. The regressions use data from 2004 through 2006 such that there are three observations for each Census tract. We include year dummies to control for the year of origination. None of the goal variables are significant at any conventional statistical significance level regardless of what 


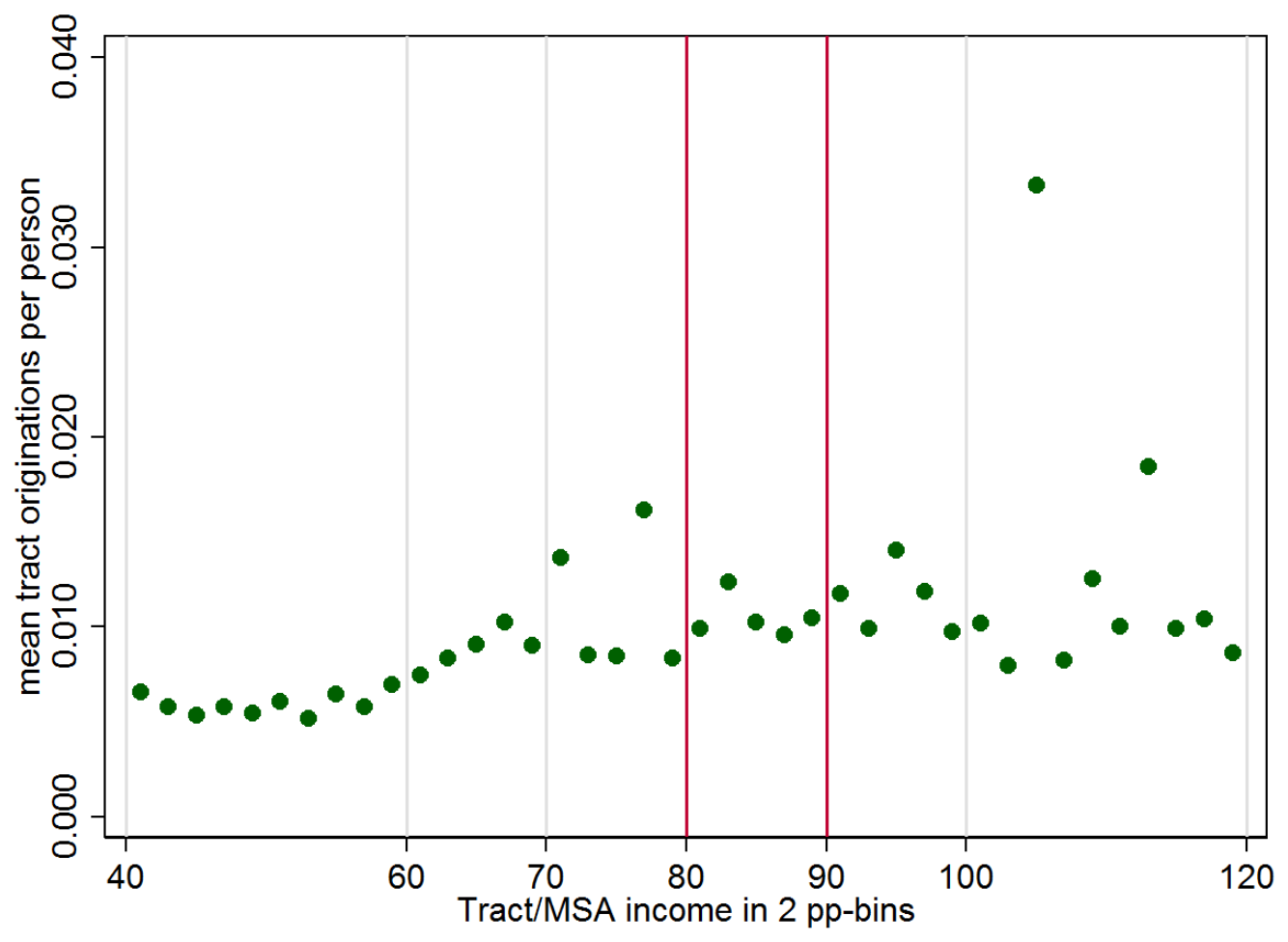

Figure 1: Effect of CRA1 and GSEs' UAG2 on 2005 Origination Volumes

Each dot represents observations in 2 percentage point intervals ranging from $40 \%$ to $120 \%$ of Census Tract/MSA Income ratio. For example, the $79 \%$ dot represents the data between $78 \%$ and the $80 \%$ cutoff. Similarly, the $81 \%$ dot represents observations in the $80 \%$ to $82 \%$ band. The regressions use only observations immediately below and immediately above the cutoff (e.g., the data represented by the $79 \%$ and $81 \%$ points for CRA1). 


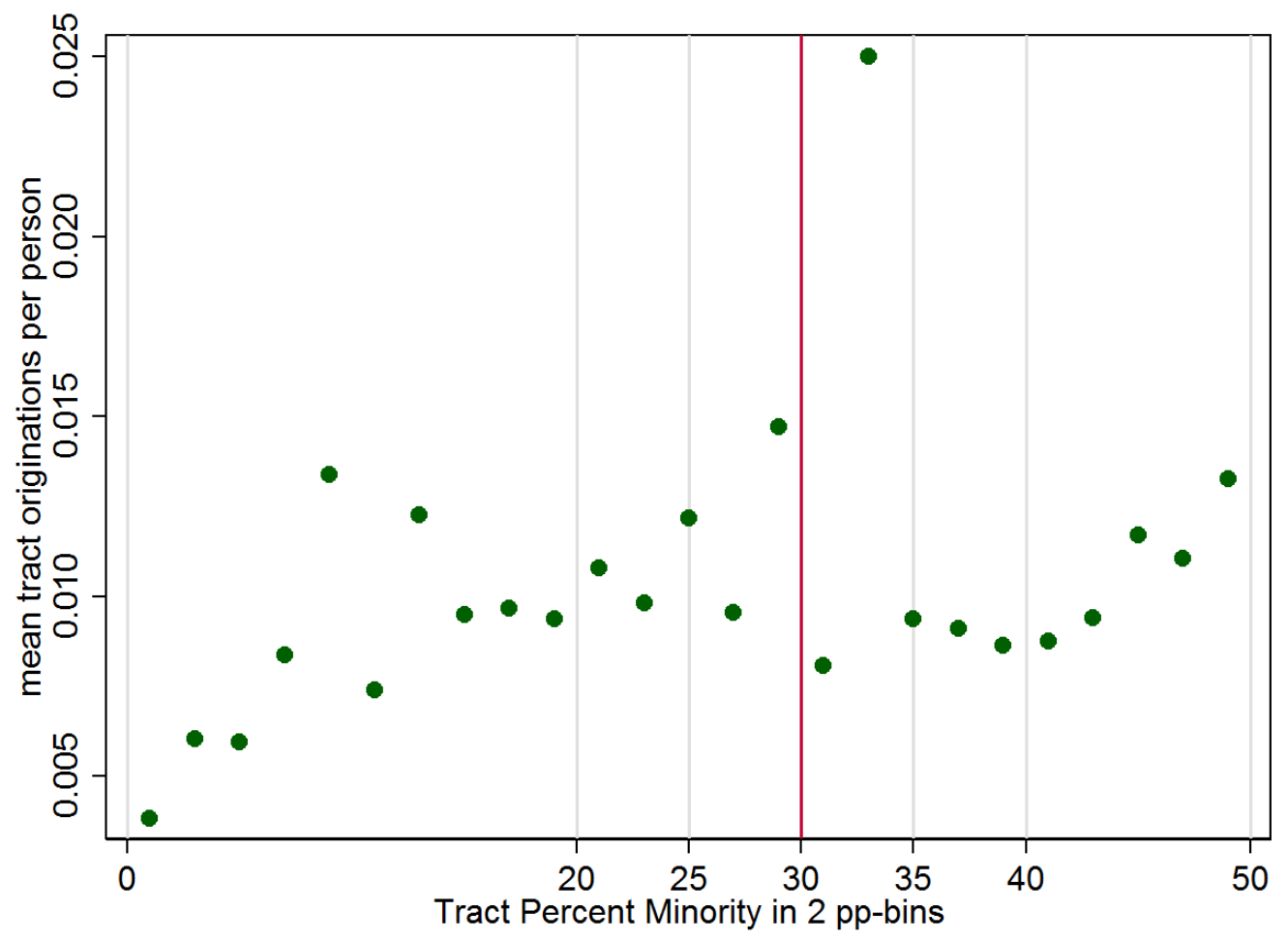

Figure 2: Effect of GSEs' UAG1 on 2005 Origination Volumes

Each dot represents observations in 2 percentage point intervals ranging from $0 \%$ to $50 \%$ of Census Tract Percent Minority. For example, the $29 \%$ dot represents the data between $28 \%$ and the $30 \%$ cutoff. Similarly, the $31 \%$ dot represents observations in the $30 \%$ to $32 \%$ band. The regressions use only observations immediately below and immediately above the cutoff (e.g., the data represented by the $29 \%$ and $31 \%$ points for UAG1). 


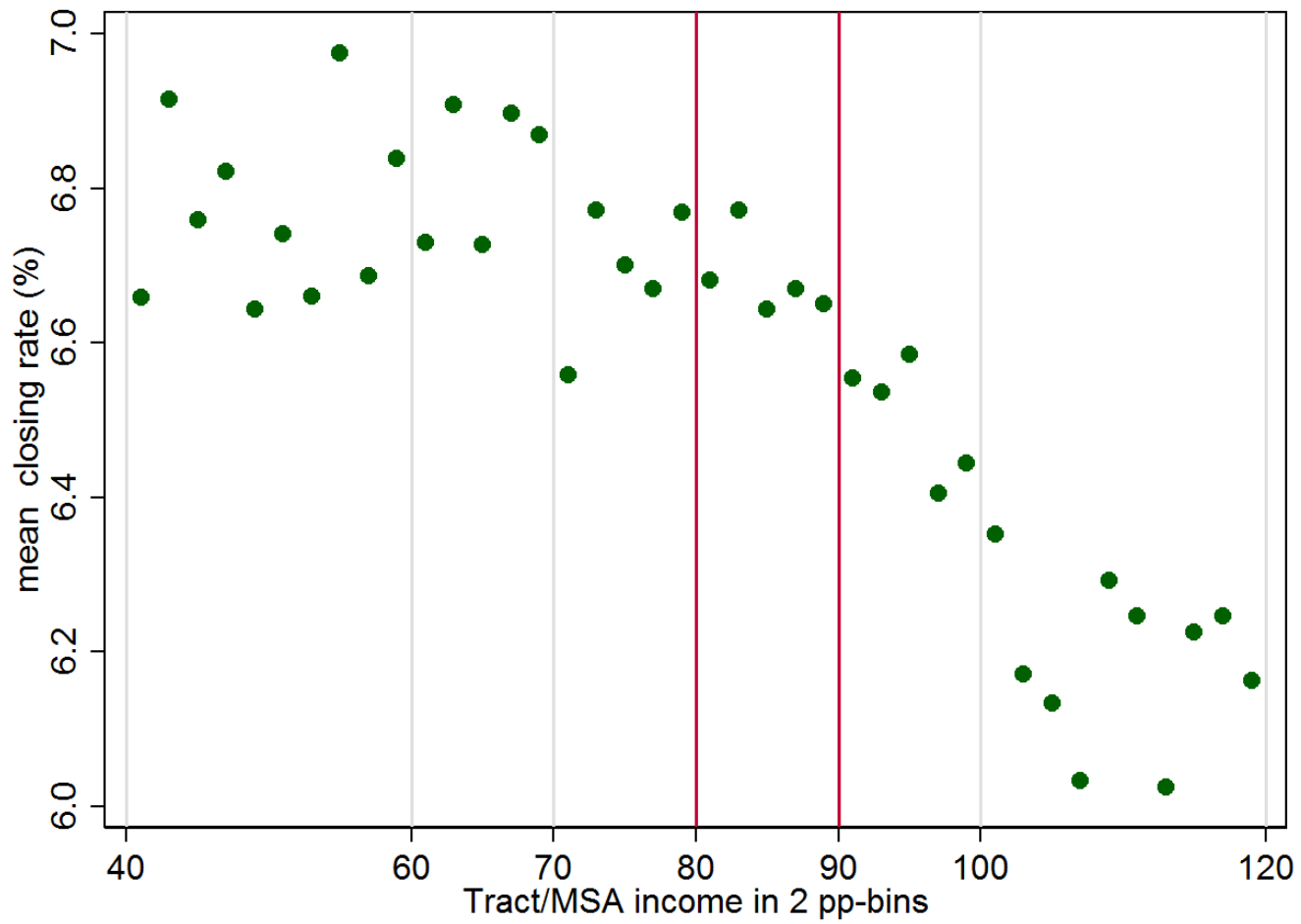

Figure 3: Effect of CRA1 and GSEs' UAG2 on 2005 Contract Interest Rates

Each dot represents observations in 2 percentage point intervals ranging from $40 \%$ to $120 \%$ of Census Tract/MSA Income ratio. For example, the $79 \%$ dot represents the data between $78 \%$ and the $80 \%$ cutoff. Similarly, the $81 \%$ dot represents observations in the $80 \%$ to $82 \%$ band. The regressions use only observations immediately below and immediately above the cutoff (e.g., the data represented by the $79 \%$ and $81 \%$ points for CRA1). 


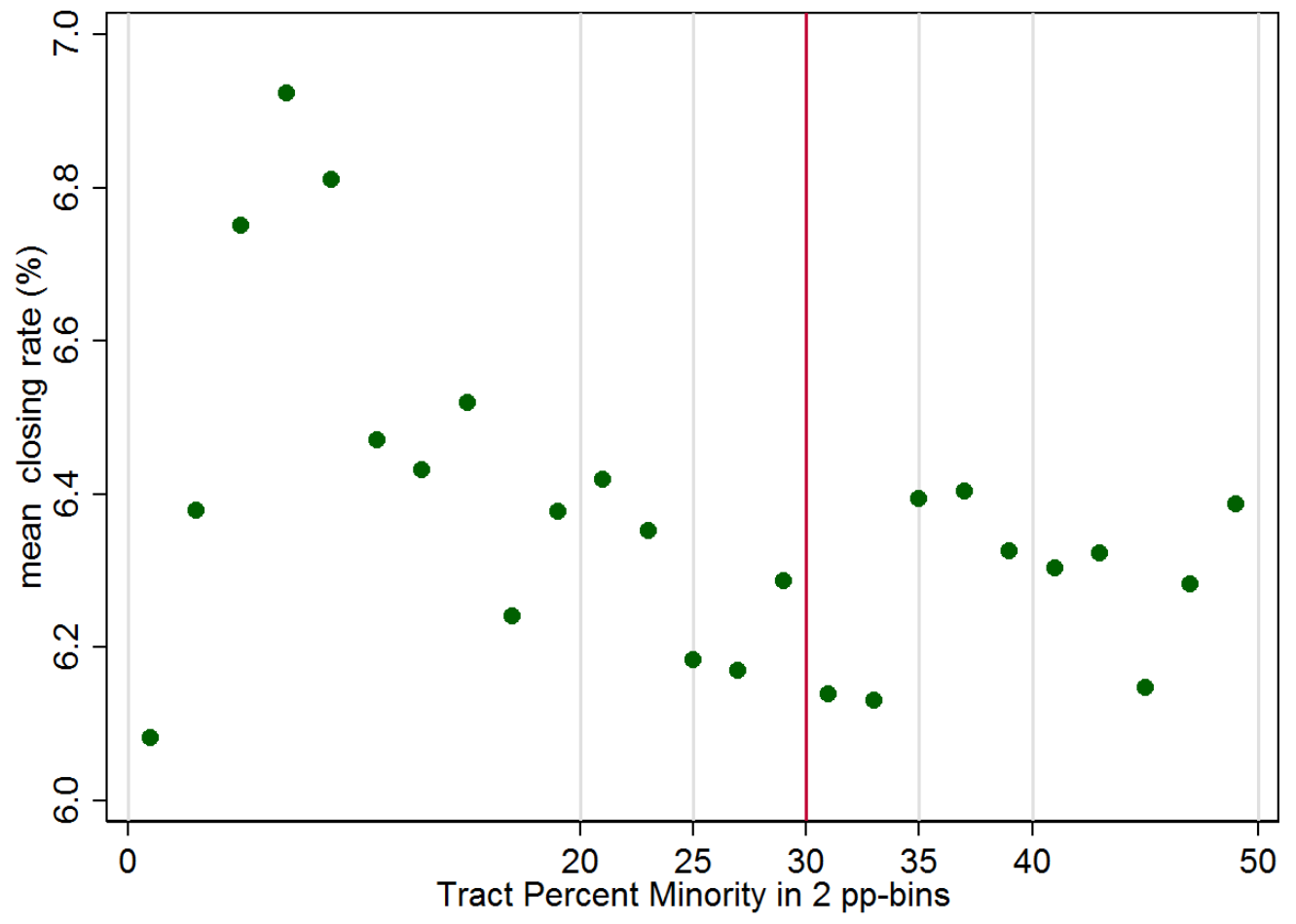

Figure 4: Effect of GSEs' UAG1 on 2005 Contract Interest Rates

Each dot represents observations in 2 percentage point intervals ranging from $0 \%$ to $50 \%$ of Census Tract Percent Minority. For example, the $29 \%$ dot represents the data between $28 \%$ and the $30 \%$ cutoff. Similarly, the $31 \%$ dot represents observations in the $30 \%$ to $32 \%$ band. The regressions use only observations immediately below and immediately above the cutoff (e.g., the data represented by the $29 \%$ and $31 \%$ points for UAG1). 


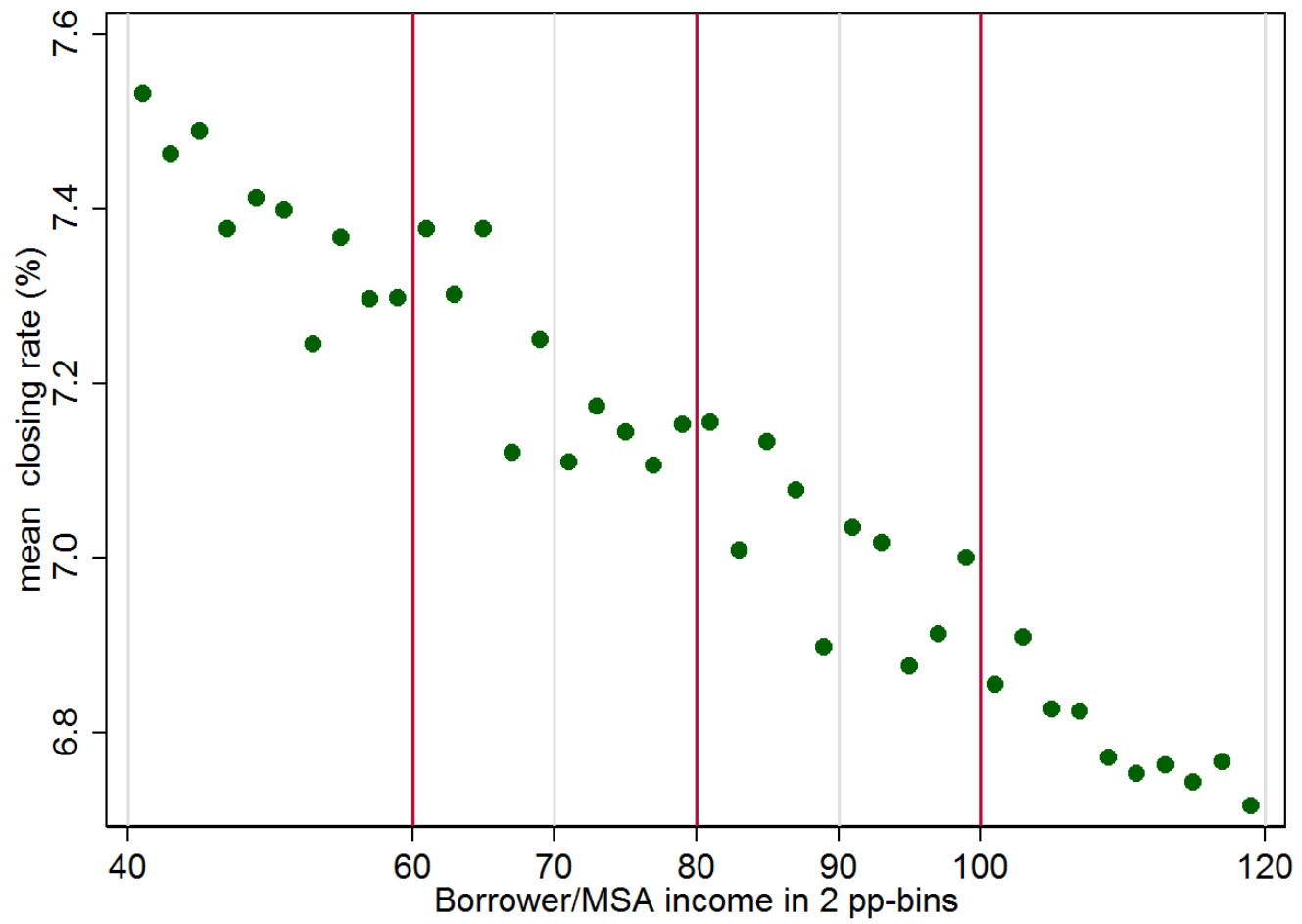

Figure 5: Effect of CRA2 and GSEs' SAG1, SAG2, and LMIG on 2005 Contract Interest Rates Each dot represents observations in 2 percentage point intervals ranging from $40 \%$ to $120 \%$ of Census Tract/MSA Income ratio. For example, the $79 \%$ dot represents the data between $78 \%$ and the $80 \%$ cutoff. Similarly, the $81 \%$ dot represents observations in the $80 \%$ to $82 \%$ band. The regressions use only observations immediately below and immediately above the cutoff (e.g., the data represented by the $79 \%$ and $81 \%$ points for CRA1). 
controls we include.

Although we do not find an effect of affordable housing mandates on origination volumes, the volume of originations is not well suited to studying the borrower-level goals using our data. The main reason is that it is unclear what the right denominator would be. One way the goals might manifest themselves is by borrowers receiving a lower interest rate if they meet one or more of the program goals. Alternatively, affordable housing policies may lead to lenders holding borrowers to a lower ex ante qualification standard relative to ex post performance because of the benefit lenders receive by complying with the affordable housing policies. To look at the borrower-level goals, we thus also look at the effect of affordable housing goals on interest rates and default.

Table 4 presents the results from our regression of the contract interest rate, measured in percentage points, on the goal variables and controls. The goal indicator variables are usually insignificant and small in magnitude. For three goals, the goal indicator variable is statistically significant: UAG1, SAG1, and LMIG. However, in two of the three cases (UAG1 and LMIG), the sign of the goal variable is positive such that the results suggest that the affordable housing goal increases rather than lowers the cost of borrowing for eligible borrowers. Furthermore, the effect of the goals on the cost of borrowing is never significant once we include a broader set of controls for loan-level characteristics. ${ }^{11}$

Table 5 illustrates the effect of the affordable housing goals on ex post loan performance. The dependent variable in the probit is an indicator variable that takes a value of 1 if the loan goes into serious default (i.e., experiences a delinquency of 90 days or more or terminates through foreclosure) within two years of origination. The table shows the marginal effects of a change in the dependent variable on the likelihood of default. The goal variables are statistically insignificant with two exceptions. The coefficients indicate that a loan that is eligible for the UAG2 goal by virtue of being made in a tract with median income less than or equal to $90 \%$ of that in the MSA is about $2 \%$ more likely to default. However, the effect is statistically significant only at the $10 \%$ level after we include other loan controls. Furthermore, the results in Table 5 indicate that a loan made to a borrower with income less than the median income in the MSA is $2 \%$ less likely to default than one

\footnotetext{
${ }^{11}$ The other controls are the FICO score, the LTV ratio at origination, the origination amount, a dummy for whether the loan was full documentation, a dummy for whether the loan was for refinancing, a dummy for whether the loan was originated in California, a dummy for whether the loan included PMI, and a dummy for whether the loan had a prepayment penalty.
} 


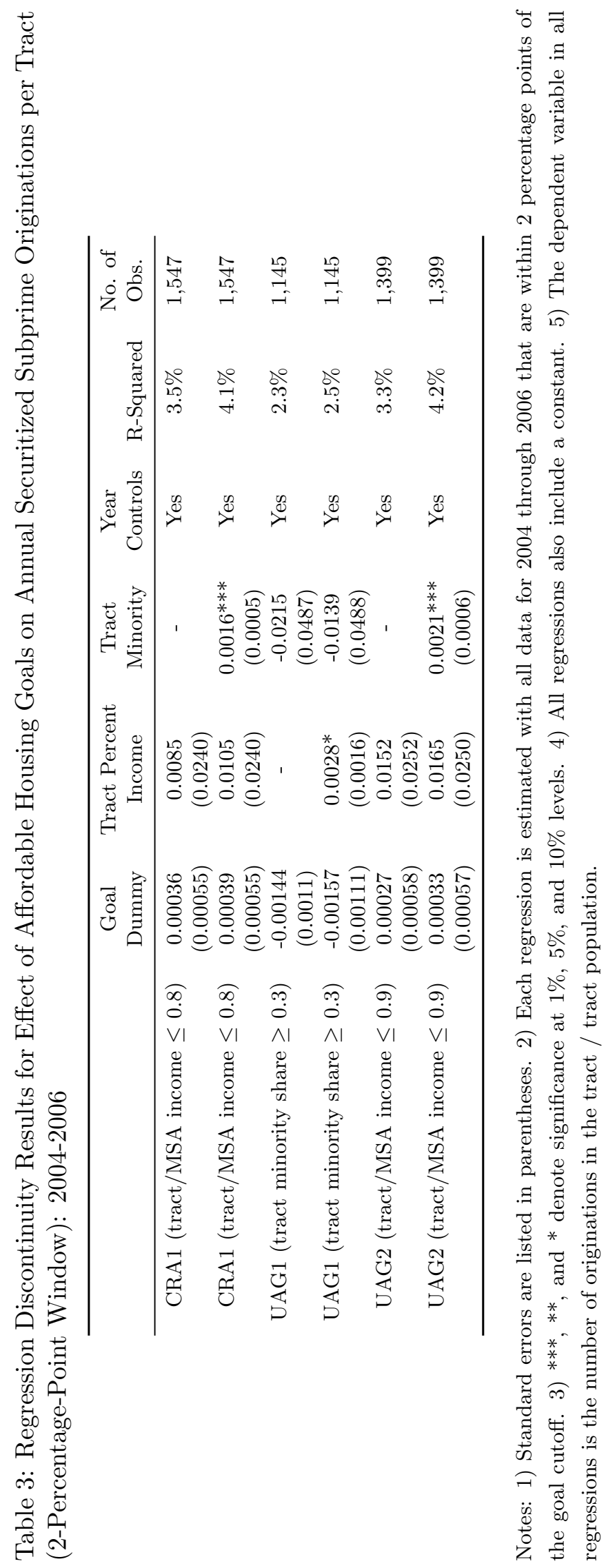




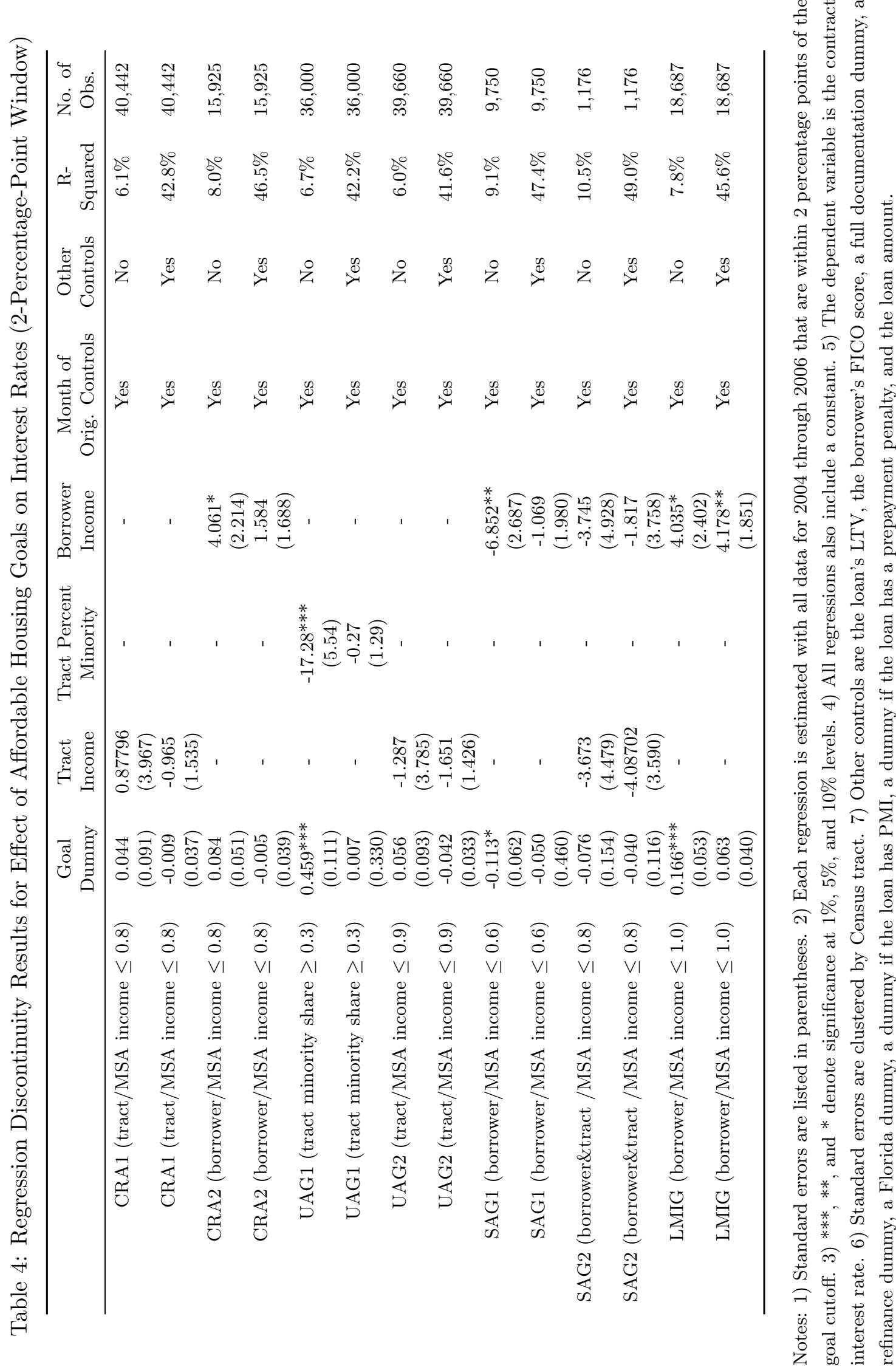


that did not qualify for the GSEs' LMIG goal. Overall, the results in Table 5 are not supportive of the notion that loans eligible for affordable housing mandates were of worse quality than those that were ineligible.

\section{Robustness}

\section{Alternative Bandwidths}

It is possible that our chosen benchmark bandwidth of 2 percentage points is not the appropriate bandwidth for one of two reasons. The first possibility is that it is too broad such that our loans are not sufficiently similar along the key dimension of interest for evaluating the goal. If this is the case, our regressions will not pick up the effect of the affordable housing program. The second possibility is that our bandwidth is too small for us to have sufficient data to detect the effect of the affordable housing programs. To ensure our results are robust to these concerns, we also explore the effect of the affordable housing goals on all three outcome measures using 1- and 5-percentage-point windows. The results are quite similar to the benchmark results and are reported in the appendix.

\section{Multidimensional Regression Discontinuity Estimates}

The goals are not mutually exclusive, i.e., a loan that already satisfies one goal is more valuable if it satisfies a second or third goal, such that our one-dimensional, goal-by-goal approach to evaluating the effect of the goals is valid. However, we may be able to gain more power by comparing loans that satisfy two or more goals with loans that satisfy one or no goal. In most cases, a loan that is near the threshold of two goals could satisfy one geographic and one borrower-level goal. The exception is a combination of the CRA geographic goal with the UAG's racial goal. We have far fewer observations for some of these regressions since, as noted earlier, few loans in the PLMBS market were close to satisfying the borrower-specific goals. In some cases for the SAG2 goal, we do not have enough observations to accurately estimate the multidimensional specification. The results are similar to the benchmark results and are available in the appendix.

\section{Other Specifications}

We also estimated the model separately for 2004, 2005, and 2006 to see whether the goals had influenced the PLMBS market in any particular year. We found no substantive difference in the results from our benchmark. These results are available in an online appendix. We furthermore 


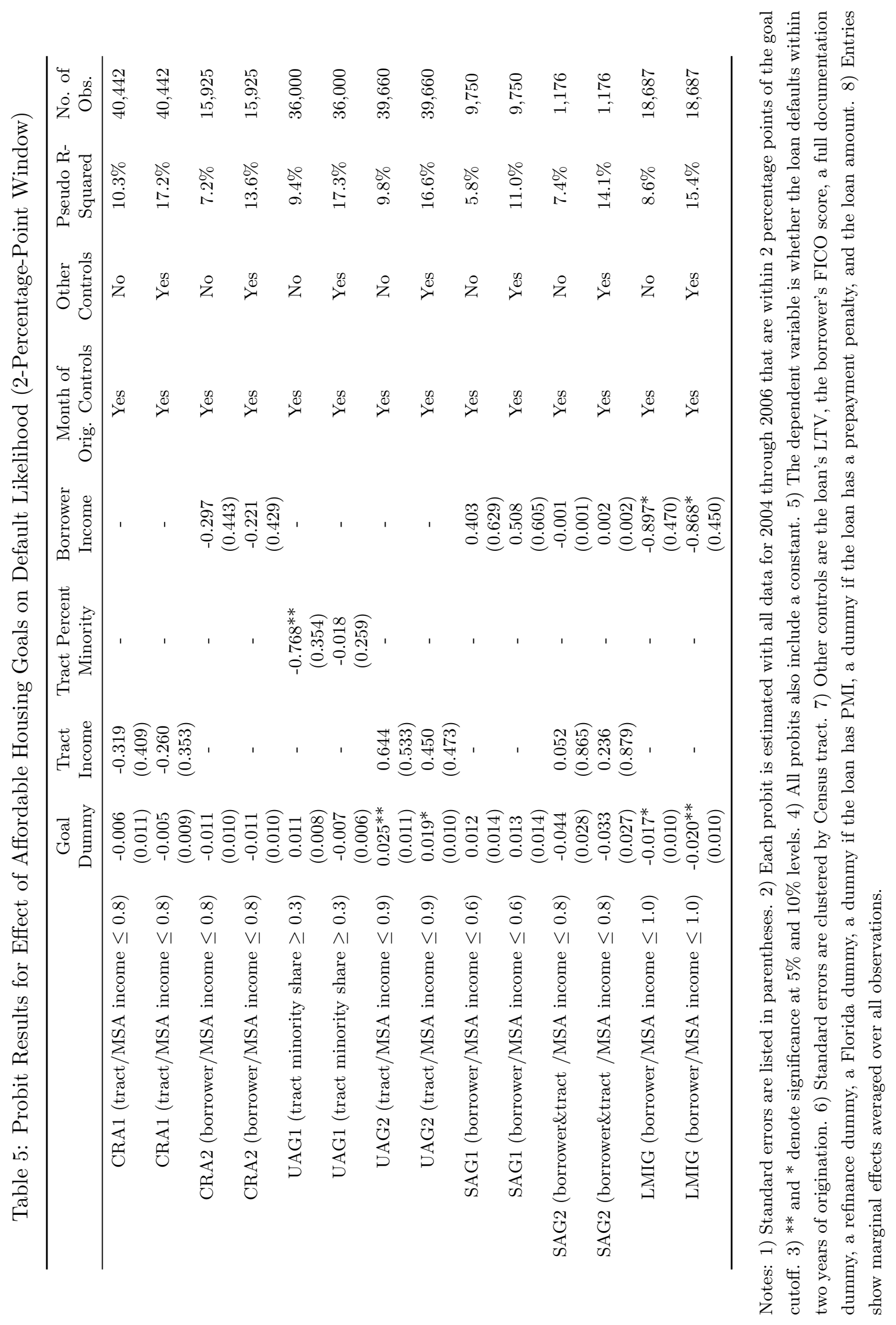


examined whether our results differ when we estimate the model on other product types. We looked at the next two most common products in our sample which are 1) adjustable rate loans that are interest only for five years and then fully amortizing over the next 25 years, and 2) fixed rate loans that fully amortize over 30 years. We then grouped all nonprime products in the dataset (eight products in total) and estimated the model. For the interest rate regressions and default probits, we included product dummies to control for product heterogeneity. These results are also in the online appendix. Finally, although the majority of the loans in our sample are below the conforming loan limits since our dataset does not include loans in the jumbo MBS category, we re-estimated the model using only loans below the one-unit conforming loan limits. These results were also very similar to our benchmark results.

\section{Institutional Evidence and Discussion}

Our analysis has shown no evidence of any discontinuity in the volume, pricing, or performance of subprime mortgages around the affordable housing cutoffs. One limitation of the regression discontinuity analysis is that the approach only detects a local average treatment effect. In this section, we therefore provide evidence from prospectus supplements that show why it seems unlikely affordable housing mandates caused the subprime crisis.

\section{Prospectuses}

We examined a random sample of 100 prospectus and prospectus supplements available from Bloomberg from the subprime or alt-A PLMBS deals into which our loans were packaged. We looked for 131 randomly selected deals on Bloomberg. Prospectuses for 31 deals were not available because either the deal was a private placement (4 deals), the deal prospectus was in a format that made reading and searching the document exceptionally difficult (3 deals), or the pool name in CL was not a close enough match to the pool name in Bloomberg. The Bloomberg names of the pools for which we examined the prospectuses are available in the online appendix. Subprime and Alt-A PLMBS prospectuses (including the prospectus supplement) are typically 200-300 page documents that carefully describe the deal structure and collateral characteristics using many criteria as ge-

ography, the interest rates on the mortgages, the property type (e.g., single-family or condo), the purpose of the loan (purchase or refinancing), FICO score, documentation level, and the LTVs. 
Not one of the 100 prospectus supplements we examined, however, discussed the eligibility of the loans in the pool to satisfy either the CRA or the GSE affordable housing goals. Any prospective buyer of the pools to satisfy affordable housing programs would thus have had to calculate itself for each loan whether or not it satisfied the goal. The lack of any mention whatsoever of the affordable housing programs suggests they were not important motivations for the buyers of these securities. Furthermore, the evidence from the prospectuses indicates that few, if any, nonprime PLMBS were CRA-qualified. None of the securities in our random sample state that they were CRA-qualified or provide information that would enable a depository institution or CRA evaluation to ascertain that the security is CRA-qualified. As such, banks were not, in general, able to count any loans they acquired exposure to through purchases of PLMBS towards their CRA commitments.

Our review of the sample prospectus supplements reveals clear evidence that the GSEs were significant buyers of PLMBS. In some deals, the prospectus supplement states that all of the loans in the pool conform to one of the GSEs' limits for principal balances such that the GSE mentioned could purchase the securities. In other deals, the loans are divided into two or more loan pools with one or more loan pool consisting strictly of loans with principal balances below the conforming loan limits. Rather than stating that the loans have principal balances below the conforming loan limit, which is the same for both Fannie Mae and Freddie Mac, the prospectus supplements usually state the name of one of the two GSEs when discussing the limit which strongly suggests a particular GSE as the purchaser. Some deals make it even clearer that certain securities are designed for Fannie Mae and Freddie Mac by separating the loans into separate loan groups for Fannie Mae and for Freddie Mac. For example, SAIL 2005-10 has one pool of loans, pool 1, with "principal balances that do not exceed the applicable Freddie Mac maximum original loan amount limitations", and another pool of loans, pool 2, with "principal balances that do not exceed the applicable Fannie Mae maximum original loan amount limitations".

Table 6 summarizes our findings from reviewing the random sample of 100 prospectuses. Of the 100 prospectuses, 47 state explicitly that one or more underlying loan pools consists exclusively of loans with principal balances below the conforming loan limit. The total dollar volume of these exclusively conforming pools represents $24 \%$ of the total dollar volume of all pools described in the prospectuses.

Thus, it appears that the GSEs were motivated to buy PLMBS but for some reason other than 
their affordable housing goals. As these securities were widely seen to be highly profitable during the subprime boom, and as a consequence many investors other than the GSEs bought them, the GSEs may have bought them because they offered attractive yields. Indeed, Calomiris (2011) cites internal documents with a quotation from a senior GSE executive, Donna Cogswell, expressing the view that investments in subprime were viewed as highly profitable. Adelino, Frame, and Gerardi (2014) also provide evidence that the GSEs' investments in PLMBS were more profitable than those of other PLMBS investors.

Table 6: Summary of Sample of Prospectuses

\begin{tabular}{lc}
\hline Total no. of deals & 100 \\
No. of deals that mention CRA or GSE Affordable Housing Goals & 0 \\
No. of deals with one or more pools exclusively conforming & 47 \\
Total deal volume & $\$ 100,409,451,614$ \\
Total volume of conforming-only pools & $\$ 24,494,562,317$ \\
Conforming-only share of all pools $(\$$ volume) & $24 \%$ \\
\hline
\end{tabular}

\section{Discussion}

Although we find no evidence that the affordable housing goals affected the subprime PLMBS market directly, the affordable housing goals may have affected the market indirectly. For example, the GSEs' affordable housing goals may have given the GSEs some political cover to purchase substantial quantities of PLMBS. Our results suggest that, if GSE demand for PLMBS moved the market as a whole, the goals were either not binding or the GSEs were satisfying their affordable housing goals in the prime sphere of the mortgage market.

Similarly, the GSEs may have used their affordable housing goals to convince regulators to permit them to change their underwriting standards to include low documentation and no documentation loans as Calomiris (2011) argues. While our data indicates that reduced documentation mortgages were used to exaggerate borrower income rather than to understate it, and were thus not used to increase affordable housing lending, it is unclear whether OFHEO was aware that this was the case. While we are not able to quantify the effect of the change in the GSEs underwriting policy, it seems very likely that the change encouraged risky lending both by the GSEs and other market participants.

Legislators may also have been hesitant to enact legislation to reduce risky lending during the 
boom for fear of reducing the supply of affordable housing. While such a regulatory failure is not directly due to the affordable housing legislation that we study, the attitude may have contributed to the subprime boom.

Finally, we note that our paper does not provide any proof of welfare benefits of affordable housing laws. When the goals are binding, they may reallocate resources in an inefficient manner and there may be more effective ways to achieve the intent of the laws (e.g., cash transfers to low income borrowers). Even when the goals are not binding, the sheer paperwork involved in compliance imposes costs on lenders that are surely passed on to borrowers in some form.

\section{Conclusions}

In this paper we examined the effect of affordable housing legislation on the volume, pricing, and performance of securitized subprime mortgages originated in California and Florida in 2004 through 2006. Using a regression discontinuity approach, we find no evidence that the affordable housing goals of the CRA or of the GSEs affected any of these outcome measures. This finding is robust to the inclusion of various, to the sample of only full documentation loans, and to different bandwidths for the regression discontinuity specification. We also find that the majority of mortgages packaged into subprime MBS went to borrowers with high stated income: Average borrower income for such mortgages was about $\$ 100,000$. While we provide evidence that Fannie Mae and Freddie Mac held substantial amounts of subprime PLMBS, and that their holdings of these securities played a significant role in their demise, the evidence in this paper refutes the claim that the affordable housing mandates were responsible for the subprime crisis. We hope our findings stimulate researchers to seek other explanations for the subprime securities boom.

\section{Acknowledgements}

We thank the editor, W. Scott Frame, an anonymous referee, Bob Avery, Effi Benmelech, Neil Bhutta, Charles Calomiris, Morris Davis, Ed Kung, José García Montalvo, Dwight Jaffee, Rossen Valkanov, Peter Wallison, Wenyu Zheng, and conference and seminar participants at the AFA Annual Meeting, the AREUEA Mid-Year Meeting, Baruch College, the Fall 2012 HULM meeting, the Federal Reserve Bank of Atlanta and University of North Carolina (Charlotte)'s conference on "Government Involvement in Residential Mortgage Markets", the Federal Reserve Bank of Cleve- 
land "Policy Summit on Housing, Human Capital, and Inequality", the Federal Reserve Bank of St. Louis, the Federal Reserve System Meeting on Microeconomics, the Latin American Meeting of the Econometric Society, Penn State University, the Swedish Institute for Financial Research's (SIFR) Conference on Real Estate and Mortgage Finance, the Symposium on Rethinking Mortgage-Based Homeownership at the University of Arizona (College of Social and Behavioral Based Sciences), the University of Arizona (Eller School of Management), the University of California (San Diego), and the University of Western Ontario for comments on an earlier draft. Kristie M. Engemann, Christopher Martinek, and Kate Vermann provided research assistance.

\section{References}

Adelino, Manuel, W. Scott Frame, and Kristopher S. Gerardi, 2014. "The Effect of Large Investors on Asset Quality: Evidence from Subprime Mortgage Securities." Working paper, Duke University.

Agarwal, Sumit, Efraim Benmelech, Nittai Bergman, and Amit Seru, 2012. "Did the Community Reinvestment Act (CRA) Lead to Risky Lending?" Working paper, National University of Singapore.

Ambrose, Brent W. and Thomas G. Thibodeau, 2004. "Have the GSE Affordable Housing Goals Increased the Supply of Mortgage Credit?" Regional Science and Urban Economics 34, 263-273.

Baum-Snow, Nathaniel and Justin Marion, 2009. "The Effects of Low Income Housing Tax Credit Developments on Neighborhoods." Journal of Public Economics 93, 654-666.

Bhutta, Neil, 2012. "GSE Activity and Mortgage Supply in Lower-Income and Minority Neighborhoods: The Effect of the Affordable Housing Goals." Journal of Real Estate Finance and Economics 45:1, 238-261.

Bhutta, Neil, 2011. "The Community Reinvestment Act and Mortgage Lending in LowerIncome Neighborhoods." Journal of Law and Economics 54:4, 953-983.

Bolotnyy, Valentin, 2014. "The Government-Sponsored Enterprises and the Mortgage Crisis: the Role of the Affordable Housing Goals." Real Estate Economics 42:3, 724-55.

Bostic, Raphael W. and Stuart Gabriel, 2006. "Do the GSEs matter to low-income housing markets? An assessment of the effects of the GSE loan purchase goals on California housing outcomes." Journal of Urban Economics 59, 458-475.

Calomiris, Charles, 2011. "The Mortgage Crisis: Some Inside Views." The Wall Street Journal Oct. 27, A19.

Congressional Budget Office, 2010. Fannie Mae, Freddie Mac, and the Federal Role in the Secondary Mortgage Market. Washington, DC: CBO. 
Demyanyk, Yuliya, 2009. "Quick Exits of Subprime Mortgages." Federal Reserve Bank of St. Louis Review 91:2, 79-93.

Fama, Eugene F. and Robert Litterman, 2012. An Experienced View on Markets and Investing. Financial Analysts Journal 28:6, 15-19.

Federal Reserve Bank of San Francisco, 2010. CRA Investment Handbook.

FHFA, 2010. The Housing Goals of Fannie Mae and Freddie Mac in the Context of the Mortgage Market: 1996 - 2009. Mortgage Market Note 10-2. Washington, DC.

Ghent, Andra C., Rubén Hernández-Murillo, and Michael T. Owyang, 2014. "Differences in Subprime Loan Pricing Across Races and Neighborhoods. " Regional Science and Urban Economics 48, 199-215.

Greenspan, Alan, 2010. "The Crisis." Brookings Papers on Economic Activity Spring, 201-246.

Hahn, Jinyong, Petra Todd, and Wilbert van der Klaauw, 2001. "Identification and Estimation of Treatment Effects with a Regression-Discontinuity Design." Econometrica 69:1, 201-209.

Haughwout, Andrew, Christopher Mayer, and Joseph Tracy, 2009. "Subprime Mortgage Pricing: The Impact of Race, Ethnicity, and Gender on the Cost of Borrowing." Brookings-Wharton Papers on Urban Affairs, 33-63.

HUD, 2012. "Community Development Block Grant Program - CDBG." Available at http://portal.hud.gov/hudportal/HUD?src=/program_offices/comm_planning/communitydevelopment/programs.

Jiang, Wei, Ashlyn Nelson, and Edward Vytlacil, 2014. "Liar's Loan? Effects of Origination Channel and Information Falsification on Mortgage Delinquency." Review of Economics and Statistics 96:1, 1-18.

Lee, David S. and Thomas Lemieux, 2010. "Regression Discontinuity Designs in Economics." Journal of Economic Literature 48, 281-335.

Manchester, Paul B., 2008. "Goal Performance and Characteristics of Mortgages Purchased by Fannie Mae and Freddie Mac, 2001-2005." U.S. Department of Housing and Urban Development Working Paper No. HF-017.

Moulton, Shawn, 2014. "Did Affordable Housing Mandates Cause the Subprime Mortgage Crisis?" Journal of Housing Economics 24, 21-38.

Office of the Comptroller of the Currency, Federal Deposit Insurance Corporation, Federal Reserve, and Office of Thrift Supervision, 1997. "Interpretive Letter \#794." Available at http://www.occ.treas.gov/interp/sep97/cra794.pdf.

Rajan, Raghuram, 2010. "Bankers have been sold short by market distortions." Financial Times, June 2nd.

Reid, Carolina and Elizabeth Laderman, 2011. "Constructive Credit: Revisiting the Performance of Community Reinvestment Act Lending During the Subprime Crisis." Pp. 159-186 in The 
American Mortgage System: Crisis and Reform, Susan M. Wachter and Marvin M. Smith, eds. Philadelphia, PA: University of Pennsylvania Press

Reid, Carolina, Ellen Seidman, Mark Willis, Lei Deng, Josh Silver, and Janneke Ratcliffe, 2013. "Debunking the CRA Myth - Again." Manuscript, University of North Carolina (Chapel Hill).

Ross, Stephen L. and Yinger, John, 2002. The Color of Credit: Mortgage Discrimination, Research Methodology, and Fair-Lending Enforcement. Cambridge, MA: MIT Press.

Thistlethwaite, Donald L. and Donald T. Campbell, 1960. "Regression-Discontinuity Analysis: An Alternative to the Ex Post Facto Experiment." The Journal of Educational Psychology 51:6, 309-317. 